\title{
Distance Learning in Clinical Transplantation: A Successful Model in Post-Graduate Education
}

\author{
Ahmed Halawa ${ }^{1 \& 2, *}$, Ajay Sharma ${ }^{2 \& 3}$, Julie M Bridson ${ }^{2}$, Sarah Lyon $^{2}$, Denise Prescott ${ }^{2}$, Arpan Guha ${ }^{2 \& 3}$ \& David \\ Taylor $^{3}$ \\ ${ }^{1}$ Sheffield Teaching Hospitals, Sheffield, UK \\ ${ }^{2}$ Faculty of Health and Science, Institute of Learning and Teaching, University of Liverpool, UK \\ ${ }^{3}$ Royal Liverpool University Hospitals, Liverpool, UK \\ *Correspondence: Consultant Transplant Surgeon, Sheffield Teaching Hospitals, Herries Road - Sheffield, S5 7AU, \\ United Kingdom. Tel: 44-778-754-2128. E-mail: ahmed.halawa@sth.nhs.uk
}

Received: April 29, 2017

Accepted: May 14, 2017 Online Published: June 14, 2017

doi:10.5430/wje.v7n3p74

URL: https://doi.org/10.5430/wje.v7n3p74

\begin{abstract}
Background and Purpose: There are misconceptions among clinicians and educational bodies that online courses would not suit clinically orientated medical education, where bedside management and direct contact with real patients is the key to the learning process. Whereas, the proponents of online education believe that a well-designed and properly blueprinted course can deliver the required education that would efficiently meet the expectations of both the student and these educational bodies. While variations in medical practice are a norm that warrant a flexible and, at the same time, a focused approach is required to ensure that 'threshold concepts' are learnt, which is an additional challenge. We aimed to facilitate the students to develop skills of learning from work-based reflective practice by linking with their own real-time analysis of their own clinical experience. This is supported by a robust scientific basis, a unique opportunity for many clinicians who may not have a reliable opportunity for discussion and, thereby, this course (MSc in Transplantation) provides a platform that allows everyone to learn from each other's experience by using 'e-blackboard ${ }^{\mathbb{R}}$.

Methods: Not just a knowledge transfer, the critical thresholds of each and every chapter in the 4 modules of MSc in Transplantation Sciences were defined to a razor-sharp precision. Learning objectives of learning activity were aimed to achieve constructive alignment with critical threshold. We employed Kirkpatrick pyramid (satisfaction, learning, impact, results and return on investment) (a) for the evaluation of our performance as educators of the programme, and (b) to evaluate the acceptance of this non-traditional format in clinical medicine education by postgraduate students (80 transplant clinicians from 22 countries).

Results: Students' survey of the first cohort (satisfaction, Kirkpatrick level 1) reported $93 \%$ students' satisfaction rate. $93 \%$ of the students passed module one (learning Kirkpatrick level 2) and $100 \%$ subscription to module two (return on investment Kirkpatrick level 5).

Conclusion: For a successful model in distance learning in clinical medicine it is imperative to establish an effective supportive contact using a range of modalities in order to allow real-time reflective practice that is so crucial in enabling the students to learn from their own clinical experience.
\end{abstract}

Keywords: distance learning; transplantation; and clinical education

\section{Introduction}

While distance education has been in existence for at least 100 years, the medium has changed from pencil and paper correspondence courses to real-time internet-based courses (Galusha, 1997). Some authorities use the term "open learning" to illustrate the lifelong goals of self-directed learning (Harry, 1999).

The National Health Service (NHS) in the UK is the largest employer in Europe. It expects health professionals to keep up-to-date with the fast growing and expanding medical knowledge. Given a busy NHS life with inherent difficulties in having to take time off work and to be away from the family and other domestic commitments, it is 
becoming more difficult for health professionals to attend taught courses that require them to reside away from home for lengthy periods. The same applies to health service providers in other countries, where the health system may be also suffering from resource crunch. In Asia and Africa the health professionals are even busier where the only time-off is half of a 'one-day-weekend', making it even more challenging to participate in continuing professional development (CPD) activities. Distance learning eliminates travel and accommodation costs, and enables the participants to maximize their local experience while continuing to fulfill their clinical responsibilities maintaining their on-call commitments. A further advantage is that it enables the participants to continue their life-long learning while reflecting on their 'own' clinical experience that is such a crucial factor in adult learning.

In this article, we illustrate our experience in conducting online course in clinical transplantation. This course is designed to deliver up-to-date knowledge and state-of-art clinical experience in transplantation reflecting the clinical practice of many UK as well as well-known international centres. Successful completion would lead to award a degree from the University of Liverpool (a member of Russell Group), United Kingdom. It is the first of its kind in tackling unfilled lacunae in a rapidly expanding and continuously ever-evolving subspecialty.

In many countries outside Western Europe, clinical training programme may not have well structured in transplantation, where the trainees "learn on the job" and there may not be much opportunity for 'course correction'. Even within the UK, the training is not consistent. Some units are surgeon-led with a limited role for renal physicians. Other units are mainly run by physicians with the surgeons in these units dealing only with the surgical aspect of transplantation. Ideally physicians and surgeons should be involved in mutually supportive role with inherent appreciation for each other's unique expertise and skills. We believe that providing state of the art clinical teaching in transplantation will help the clinicians, who may be marginalized into a corner of academic oblivion, to adopt an evidence-based approach role in the patient's care. The award of a university degree ensures credibility and quality assurance of the education delivered.

We implemented dynamic curriculum pedagogy to engage a diverse cohort of students. The faculty is well aware of the different learning strategies and therefore refined and tailored their approach. Some students preferred interactive clinical scenarios as their main learning strategy to align with learning objectives. Other students have been more reflective and preferred our on-line journal club. The articles that vary from meta-analysis to expert opinions-review articles with level of evidence ranging from level 1a to 5 were carefully selected to deliver a clear message based on. We provided multiple-choice questions, with a dual purpose of understanding their baseline level and to allow the students to appreciate how deep the water they are in, as they compared their own replies with a detailed explanation of the answers based on current guidelines. These additional modalities complemented with audio-visual lectures helped the faculty to continuously engage the students that addressed the dimensions not covered by the lectures. If interpreted in normal terms of engagement, normally this could even be misinterpreted giving an impression to the students as they were 'being chased' to respond when some of them have missed the interaction so crucial for reflective practice.

\section{Methods}

Four modules and the dissertation are delivered wholly online implementing an asynchronous approach to overcome the time-zone differences as it targets both UK and international students.

We maintain contact with the students using several different tools; Facebook ${ }^{\circledR}$, Skype ${ }^{\circledR}$, mobile phones and other social media, in addition to the assigned university Blackboard ${ }^{\circledR}$. This required special permission from university since it is not a normal practice to use anything other than university email. Without regular dependable contact and developing a bond, the course would fail its objective that is inherently dependent on reflective practice of their own clinical experience and statements and helping the participants into 'entering the Kolb's cycle' (Kolb, 1984). Any student who was not contributing for 2 weeks was contacted. On many occasions, they were facing 'apparently insurmountable' technical problems that were sorted by the IT department who were not contacted until these students were cajoled into taking that simple step. Small number of students experienced social circumstances and academic responsibilities that were overwhelming their lives and forced them to put their participation in this course on hold. By providing these students with clear sincere friendly advice whenever possible, it did enhance engagement and facilitated mutual learning.

We designed 3 formative coursework-based assessments per module to promote deep learning and subsequently retention of concepts. This coursework format includes poster presentation, critical appraisal of keynote article, clinical scenarios where the students is asked to formulate a treatment plan supported by scientific evidence. The students were given a feedback on the first draft. The final draft was marked to give a score along with detailed 
written feedback. We strongly believe that this form of assessment has a long-lasting outcome. This assessment strategy is suitable to assess performance (Airasian \& Russell, 2008) and evaluate a complex mechanism of developing competence and academic achievement (Linn \& Miller, 2005). It emphasizes the integration of thinking and problem solving, which is the main ethos of this course. Learners must consider and design their response rather than recall the correct answer (Linn \& Miller, 2005). This also allows direct assessment of other cognitive skills, critical analysis skills, information literacy and writing skills (Pangaro \& ten Cate, 2013). We believe that feedback is required even if there are no concerns to be addressed, the coursework was well done and there are no needs for any further improvement 'everything is $\mathrm{OK}$ '.

We focused our feedback on observable behavior such as writing style, reflection and implementation of the current evidence. This carries more weight and credibility to the students as highlighted by Gordon in 2003 . We planned the feedback to be a dialogue between the student and tutor rather than monologue with the student at receiving end. In a distance learning course, students need much more explicit feedback compared to a traditional course. The faculty is well aware of potential threat that these students might feel isolated in their virtual world and may not be able to engage properly. Narrative feedback was given formally and informally during and at the end of the course in writing and also by Skype calls or by Facebook messages. We avoided words that give sinking feeling and cause the student to switch off such as "poor" or "substandard". Narrative feedback is meaningful, explicit and more constructive as it highlights the positive as well as areas of improvement (Huta, 2010), with one exception when the faculty corrected that error of 'hypercritical feedback' immediately by the faculty members by giving phone call in addition to emails.

We promoted and supported all those students, whose coursework was rated high, to be published in peer-reviewed journals. All high performing students, identified on the basis of excellence of their assignments, were encouraged to submit their abstracts to international academic meetings. This course was used as an excellent opportunity for imparting real-time practical lessons in making them aware of teaching copyrights and respect virtues of academic honesty. There has been a strong emphasis on promoting development of robust critical appraisal and summarization skills. The students realized that their effort would not be wasted encouraging them to work harder due to the added value of this published work to their careers. 18 papers and 11 abstracts were published at the time of writing this article based on the work of students $(\mathrm{n}=80)$ in two cohorts.

We provided individualized and regular updates to each student on their performance. For example, contacting students praising them for their contributions to the web-based presentation encouraging them to contribute more. We contacted students who were not performing well to identify and resolve the problems they might be facing and to promote their engagement. Students were offered an opportunity to resubmit any substandard assignments to encourage reflection and subsequently deep learning.

Not surprisingly, when students failed the assessment and needed resubmission (7 students) it was not because of lack of knowledge, but because of behavioral issues such as poor communication, inadequate reflection, sub-standard grammatical skills, poor academic writing and failure to engage during the learning process. The lack of personal insight into professional boundaries was a cause of concern in one student. Failure to demonstrate sound and professional implementation of the national guidelines is considered underperformance. We continually emphasized the need to implement the knowledge rather than just regurgitate information.

When we identified any signs of underperformance, usually the lack of engagement was the first sign; we notified the student with our concern and tried to rectify the underlying factors before it resulted in an assignment failure. We advised the students to submit a draft before the final submission. This helped to rectify most of the underlying causes of underperformance and gave them confidence that they were not abandoned unsupported. If students failed an assignment, more intense mentoring was instated with an escalation of the level of communication between the course faculty and the student to help achieving the learning objectives (Norcini, 2003). Giving the international nature of this course ( $\mathrm{n}=22$ countries), this required availability outside the UK working hours.

\section{Results}

The students have completed the first module. The final score for module two was not available at the time of writing this article. We have used module one results to assess achievement of our objectives and students' satisfaction with this distance education in clinical medicine as suggested by Halawa and colleagues in 2017. We have used the Kirkpatrick training evaluation model (Kirkpatrick, 1967) to measure the effectiveness of our training in an objective way as follow (see figure 1):

- End-term Survey (Satisfaction: Kirkpatrick level 1): 
Twenty-six responses received (93\%). The survey covered the domains of organization, teaching, assessment and support and demonstrated excellent satisfaction (80\% strongly agreeing, $20 \%$ agreeing with satisfaction in each domain. No student was unsatisfied with any of the items screened.

- $\quad$ Success rate (Learning; Kirkpatrick level 2):

Twenty-eight postgraduate students subscribed to module 1 . Seven had to resit one or 2 assignments. Twenty-six students passed module 1 and subscribed to module 2 ( $93 \%$ success rate).

- It was difficult and even not practical to assess the change in behaviour as a result of learning (i.e., at Kirkpatrick level 3). It would be difficult for the course faculty to evaluate the students at their workplaces objectively giving the international nature of the course.

- At the time of writing this article, 16 articles were published in peer-review journals and 7 abstracts were presented in international conferences at the time of writing this article based on module lassignments of the first cohort of students. This may help in promoting the international ranking of our institute that can be interpreted as equivalent to 'change in behavior positively affecting the organization (i.e., at Kirkpatrick level 4).

- Students subscribed to next module towards the degree (Return on investment, Kirkpatrick level 5): Twenty-six subscribed to module $2(100 \%)$.

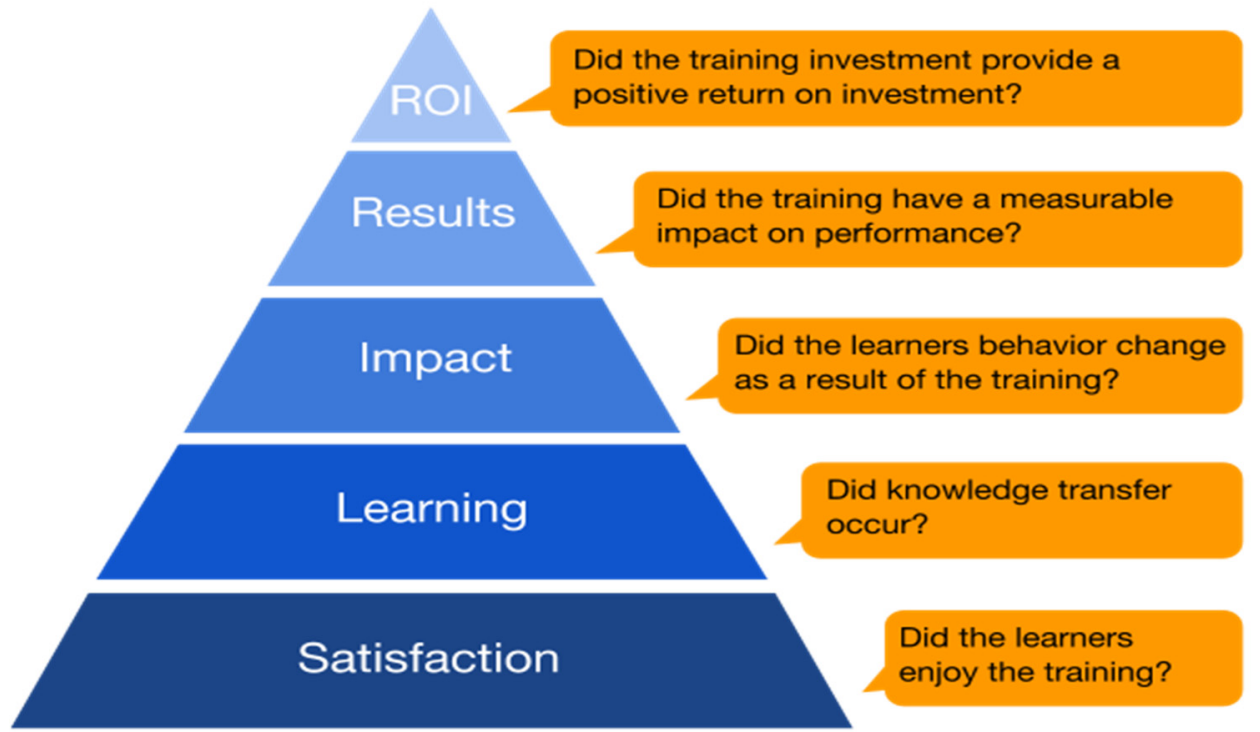

Figure 1. Kirkpatrick Pyramid for Programme Evaluation (after Phillips 1996). ROI - return on investment

\section{Discussion}

This newly introduced online course is a great example demonstrating that it is an immensely useful tool to blend theory with clinical practice. It is possible to deliver high quality online clinical education provided that it is well designed and taking into account the student's expectation and the educational needs of the tutors as suggested by Khaleghitabar and colleagues in 2016. The interactive nature, the most attractive aspect of this education, has allowed us to bridge the time and distance barriers to deliver high quality education as suggested by Edwards in 2016 and Thumé and colleagues in 2016. Boosting the curriculum with a wide range of experiences from the different UK and international centres enriched the educational value of the course. The multidisciplinary approach and the variety of educational tools used (audio lectures, bedside clinical scenarios, comprehensive multiple choice questions based on validated guidelines and high quality and leading articles) satisfied the needs of students and matched their learning style to achieve the leaning objectives. We used different tools and a range of modalities, though not new by any means but normally nor allowed by university rules, in this model. End-of-the-term survey, the pass rate of those students who engaged with the learning process and the transition of all the students who passed the first module to the next module are convincing that education in clinical medicine still can be delivered in distance learning format. This approach helped us to direct the education in the next modules. 


\section{Conclusions}

Based on our experience in delivering distance-learning education in clinical transplantation, a specialty that is rather difficult to teach and train using online methods, we strongly believe that a properly designed and blueprinted distance learning courses can cross the international borders and bridging the time zone barriers while delivering high quality education. For a successful model in distance learning in clinical transplantation it is imperative to establish an effective channels of unbroken link with students and develop a bond using a range of modalities to allow real-time reflective practice of their own clinical work and, thereby, facilitating students to enter into Kolb's cycle. It is the time for well-designed distance learning in clinical medicine to replace the traditional "chalk and blackboard" education.

\section{References}

Edwards, E. (2016). 5 Lessons for Designing Engaging E-Learning Interactions . . . From Project Runway. Retrieved from https://www.td.org/Publications/Blogs/Learning-Technologies-Blog/2016/02/5-Lessons-for-Designing-Engagin g-E-Learning-Interactions-from-Project-Runway

Galusha, J. M. (1997). Barriers to Learning in Distance Education. Computing and Technology Journal, 5(3), 6-14.

Gordon, J. (2003). ABC of Learning and Teaching in Medicine: One to one teaching and feedback. BMJ., 8, 326: $543-5$.

Halawa, A., Sharma, A., Bridson, J. M., Prsecott, D., Lyon, S., Guha, A., \& Taylor, D. (2017). How online coursework improves the attainment in clinical transplantation. The Online Journal of Distance Education and e-Learning, 1(5), 56-61.

Harry, K. (ed) (1999). Higher Education Through Open and Distance Learning. London, Routledge with the Commonwealth of Learning. https://academic.regis.edu/ed205/kolb.pdf

Huhta, Ari. (2010). Diagnostic and Formative Assessment. In Spolsky, Bernard and Hult, Francis M., The Handbook of Educational Linguistics. Oxford, UK: Blackwell. pp. 469-482.

Khaleghitabar, M., Bahador, H., Bandehagh, A., \& Shoaleh, B. (2016). Educational needs of faculty members of basic sciences of faculty of medicine: educational and personal development needs. Journal of Medical Education Summer, 15(3), 115-23.

Kirkpatrick, D.L. (1967). Evaluation of Training. In R. Craig \& I. Mittlel (Eds.), Training and Development Handbook. 87-112. New York: McGraw-Hill.

Kolb, D. A. (1984). Experiential learning: experience as the source of learning \& development. Upper Saddle River, NJ; Prentice-Hall (1984).

Linn, R. L., \& Miller, M. D. (2005). Measurement and assessment in teaching (9th Ed.). Upper Saddle River, NJ: Prentice Hall.

Norcini, J. J. (2003). Work based assessment. BMJ., 5, 753-5.

Pangaro, L., \& Ten Cate, O. (2013) Frameworks for learner assessment in medicine: AMEE Guide No. 78. Med Teach., 35(6), 1197-210. https://doi.org/10.3109/0142159X.2013.788789

Russell, M. K., \& Airasian, P. W. (2012). Classroom assessment: Concepts and applications (7th ed.) (pp. 249-299). New York, NY: McGraw-Hill.

Thumé, E., Wachs, L. S., Soares, M. U., Cubas, M. R., Gastal, A. G., Tomasi, E., Fassa, A. G., \& Facchini, L. G. (2016). Physicians' reflections on the personal learning process and the significance of distance learning in family health. Cien Saude Colet, 21(9), 2807-14. 